\title{
INCREASED NUTRIENT SOLUTION CONCENTRATION DURING EARLY FRUIT DEVELOPMENT STAGES ENHANCES PUNGENCY AND PHENYLALANINE AMMONIA-LYASE ACTIVITY IN HOT CHILI (CAPSICUM ANNUUM L.)
}

\author{
Parichat Dittakit and Thammasak Thongket \\ Department of Horticulture, Faculty of Agriculture at Kamphangsaen, \\ Kasetssart University, Nakhon Pathom, Thailand
}

Received 2013-07-24; Revised 2013-09-09; Accepted 2013-12-27

\begin{abstract}
The effect of increased nutrient concentration during different fruit development stages on the yield, pungency and PAL enzyme activity in hot chili cv. 'Super hot' was studied during August 2009-January 2010. The seedlings were planted in plastic containers containing $20 \mathrm{~L}$ of coconut-coir-dust substrate placed inside a plastic-roofed net house and received Resh's Tropical Dry Summer nutrient solution at a constant concentration (measured by Electrical Conductivity, EC) of $1.2 \mathrm{mS} \mathrm{cm}^{-1}$ during the vegetative stage and 2.4 $\mathrm{mS} \mathrm{cm}{ }^{-1}$ during the first week of blooming. Then, they were divided into treatments: Treatment 1 (control), plants continuously received nutrient solution at a constant concentration of $2.4 \mathrm{mS} \mathrm{cm}^{-1}$ until end of harvest, while treatments 2-6 received nutrient solution with a change in concentration from EC 2.4 to 3.6 $\mathrm{mS} \mathrm{cm}^{-1}$ at 1, 2, 3, 4 and 5 weeks after the week of first bloom, respectively. The results showed that the increase in nutrient concentration at different fruit development stages did not significantly influence chili fruit characteristics and yield. However, the oleoresin, capsaicin, dihydrocapsaicin and capsaicinoid contents increased significantly when hot chili plants received the nutrient concentration increase at the $1 \mathrm{st}$ and 2nd week after first bloom. Phenylalanine ammonia lyase activity in the full-ripening fruits increased significantly when the nutrient solution concentration increase occurred at 1 st and 2nd weeks after first bloom. The highest PAL activity of 827.48 mmole $\mathrm{mg}^{-1}$ protein was recorded in full-ripened fruits, when the nutrient concentration increase occurred at the 2 nd week after bloom.
\end{abstract}

Keywords: Electrical Conductivity, Pungency, Phenylalanine Ammonia-Lyase (PAL), Salt-Induced Water Stress

\section{INTRODUCTION}

Each year, Thailand exports approximately 14,644 t of processed chili produce which is worth THB 205.5 million. However, Thailand has to import approximately $2,662 \mathrm{t}$ of dried chili per year which is worth THB 31 million (Customs, 2013) due to the quality of the majority of domestic dried chili being lower than that required by food processing factories (Lertrat, 2007). It lacks pungency and color uniformity and some is contaminated with diseased and insect-infected fruits (Prinya et al., 2009; Lertrat, 2007). These fruit quality problems are caused by variations in cultivars and cultural practices used by Thai farmers as well as the unfavorable growing environment (Panklang, 2004).

Protected-environment cultivation such as growing plants in a greenhouse has been recognized as a cultivation method to protect a crop from pests and an unfavorable environment resulting in improved plant growth and yield and a higher quality of the product

Corresponding Author: Thammasak Thongket, Department of Horticulture, Faculty of Agriculture at Kamphangsaen, Kasetssart University, Nakhon Pathom, Thailand 
than growing plants under outdoor conditions (Albright, 2002; Jensen, 2002; Moller et al., 2004). Margarita and Yahia (1998) found that Habañero chili plant grown in a greenhouse had higher pungency than if grown outdoors. Moreover, when growing plants in the greenhouse, irrigation and fertilization are easy to manage and their efficiency is much higher than in outdoor growing (Summer, 2012). Therefore, growing hot-chili using a soilless culture technique inside a greenhouse can be an alternative solution to protect chili plants from pests and unfavorable conditions for Thailand; meanwhile, irrigation and fertilization can be optimized through nutrient solution management during plant growth and development to control yield and pungency. However, the information regarding nutrient management for controlling pungency of hotchili grown in the greenhouse under Thailand environmental conditions is still limited.

The pungency of chili fruit derives from organic compounds called capsaicinoids, the derivative phenylpropanoids of which capsaicin $(69 \%)$ and dihydrocapsaicin (22\%) are the major components (Bosland and Votava, 2012). All compounds are synthesized through the Phenyl Propanoid pathway and Valine pathway. Phenylalanine as the initial precursor in the Phenylpropanoid pathway is converted to cinnamic acid by PAL before it is further converted to p-coumaric acid, caffeic acid, ferulic acids, vanillin and vanillylamine, respectively and finally it is integrated with different branched chain fatty acyl moieties from the Valine pathway to render each one of the capsaicins and its analogs (Narasimha et al., 2006). The PAL activity in green-mature hot-chili fruit is less than in full-ripened hot-chili fruit and gradually increases as the fruit maturity increases and reaches its maximum value when the fruit is at the full-ripened stage (Barceloux, 2009; Hall et al., 1987; Panklang, 2004). Hall et al. (1987) reported that capsaicinoids begin to accumulate as soon as the chili fruit forms and the concentration reaches their maximum values when the fruit is at the full-ripened stage. Therefore, the PAL activity in hot-chili fruit is directly related to its pungency (Sung et al., 2005). There are other factors than the development stage that affect the pungency of chili fruit, such as the plant cultivar, environmental conditions (Barceloux, 2009), growing conditions (Sung et al., 2005) and stress conditions (Estrada et al., 1999). Estrada et al. (1998) reported that plant nutrition played a role in the synthesis of hot chili pungency. Capsaicin and dihydrocapsaicin were highest when the chili plant (Capsicum annuum $\mathrm{L}$ ) received a $\mathrm{N}$ level of 15 milli molar while they were lowest when the plant received only a 1 milli molar of $\mathrm{N}$. Water stress was also found to affect hot chili pungency. Estrada et al. (1999) found that $C$. annuum Padrón plants subjected to either drought or water logging stress produced higher levels of capsaicin and dihydrocapsaicin than control plants and the highest value was found in plants subjected to drought stress. Sung et al. (2005) explained that the increase in capsaicin synthesis in water-stressed chili plants is a defensive mechanism to cope with stress conditions and whereby the PAL is stimulated by the stress conditions. There was evidence that changing the nutrient solution concentration from 2.4 to $4.8 \mathrm{mS} \mathrm{cm} \mathrm{cm}^{-1}$ in the week of first bloom increased the oleoresin (the chili-oil extract) and capsaicinoid contents but it caused flower drop in C. annuum 'KOR 60101' grown in substrate culture (Sritong-on, 2009). It was explained that increasing the nutrient solution concentration caused salt-induced water stress to the plant. However, the degree of stress might be excessive and the application time might not be appropriate, lead-ing to flower drop and consequently yield loss. Therefore, it might be possible to stimulate or control capsaicin synthesis by introducing a lower degree of water stress at a more appropriate time i.e., after fruit set so as to avoid flower drop and yield loss.

Therefore, this study aimed to investigate the effect of the timing to impose salt-induced water stress by increasing the nutrient solution concentration during the fruit development period on the yield, oleoresin content, capsaicinoids contents and Phenylalanine Ammonia-Lyase (PAL) activity in hot chili cv. 'Super hot' grown in a greenhouse.

\section{MATERIALS AND METHODS}

Hot chili (C. annuum L.) cv. 'Super hot' seedlings were planted in plastic containers containing $20 \mathrm{~L}$ of coconut-coir-dust substrate placed inside a plasticroofed net-house at the Department of Horticulture, Kasetsart University, Nakhon Pathom Province. They received Resh's Tropical Dry Summer nutrient solution with an Electrical Conductivity (EC) of $1.2 \mathrm{mS} \mathrm{cm}^{-1}$ during vegetative growth and $2.4 \mathrm{mS} \mathrm{cm}^{-1}$ during the First week of Bloom (FB) before they were subjected to different treatments in which the timing of the application of increased Nutrient Solution 
Concentration (NSCI) during the fruit development stage. The experiment used a completely randomized block design consisting of six different timings of the application of the increased nutrient solution concentration, with each treatment replicated four times. In treatment 1 (control), plants continuously received the nutrient solution with a constant concentration of $2.4 \mathrm{mS} \mathrm{cm} \mathrm{cm}^{-1}$ until the end of harvest. In treatments 2-6, plants received the nutrient solution with concentration increased from 2.4 to $3.6 \mathrm{mS} \mathrm{cm}^{-1}$ at 1, 2, 3, 4 and 5 weeks after FB, respectively, until the end of the harvest period. All plants received an equal amount of nutrient solution every day. The volume was controlled to ensure a sufficient amount was applied by observing $10-20 \%$ drainage of the daily applied-volume; insecticide and fungicide were sprayed as needed. The air temperature and relative humidity in the greenhouse were recorded using a data logger. All fruits were harvested at the full-ripened stage and assessed for fruit characteristics, yield and pungency analysis including PAL activity analysis, with the latter also assessed in the fruits at the green mature stage. Fruit samples were dried, ground and extracted in methanol for analysis of the oleoresin content according to Prapanoppasin (2001). The capsaicin and dihydrocapsaicin contents in the oleoresin were determined by the High Performance Liquid Chromatography method (Collins et al., 1995). The PAL activity in hot-chili fruits at the green mature and full-ripened stages was determined following the method of Faragher and Chalmers (1977) and protein was analyzed using the method of Bradford (1976).

\section{RESULTS AND DISCUSSION}

The temperature and relative humidity of the air in-side the net house during the experiment period ranged from 26 to $31^{\circ} \mathrm{C}$ and from 64 to $94 \%$, respectively, (data not shown) which were in the range of optimum condi-tions for hot chili growing (Rubatzky and Yamaguchi, 1997). In this study, chilli plants received the nutrient solution with the normal concentration $\left(1.2 \mathrm{mS} \mathrm{cm} \mathrm{cm}^{-1}\right)$ during the vegetative stage and then at $2.4 \mathrm{mS} \mathrm{cm}^{-1}$ during $\mathrm{FB}$; then after $\mathrm{FB}$, they were divided into groups and subsequently, each group was subjected to NSCI at different fruit development stages. The results revealed that NSCI treatments after FB did not adversely affect the fruit characteristics nor was the yield of hot chilli cv 'Super hot' different when compared with the control treatment. However, it significantly affected the oleoresin content and pungency as well as the PAL actitivty of the hot chilli fruits.

The study of fruit characteristics and yield showed that NSCI during the diferent fruit development stages did not caused the significant diference in the fruit width but the fruit length is reduced when the NSCI was imposed at 3 weeks after FB. The fruit fresh and dry weight were not affected by the NSCI treatments, although the slight increase, but not significance, of both were noticed when the NSCI occurred at 4 and 5 weeks after FB (Table 1). Fruit number per plant and yild per plant were also not significant different as the effect of the NSCI treatments (Table 2).

The results from the pungency analysis clearly showed that increasing the nutrient concentration from 2.4 to $3.6 \mathrm{mS} \mathrm{cm} \mathrm{cm}^{-1}$ at different fruit development stages caused significant differences in the oleoresin, capsaicin, dihydrocapsaicin and capsaicinoids contents. Increasing the nutrient solution concentration during fruit development as early as the 1 st and 2nd week after FB significantly increased the oleoresin content and capsaicin and dihydrocapsaicin contents as well as the capsaicinoid content, the sum of the last two compounds. In contrast, if the concentration increase occurred in the later stage (3 weeks or more after FB), it caused a significant decrease in the capsaicin and dihydrocapsaicin contents when compared with the control treatment (un-changing concentration) as shown in Table 3.

In the current experiment, NSCI treatments caused significant changing in the PAL activity of the hot chilli fruits in both the green-mature and full-ripened stages. In the green-mature stage, the increase in the nutrient solution concentration in the 1 st and 2 nd weeks after FB did not cause any change in the PAL activity, but the increased nutrient solution concentration in the 3rd week onward after FB caused a significant decrease in the PAL activity compared with the control treatment. In contrast, in the full-ripened stage, the increase nutrient solution concentration as early as one week onward after FB could have caused a significant increase in the PAL activity compared with the control treatment. The highest activity was found when the increased nutrient solution concentration occurred in the 1 st and 2 nd weeks after FB (Table 4). 
Table 1. Fruit characteristics of hot chili cv 'Super hot' affected by the nutrient solution concentration changing from 2.4 to $3.6 \mathrm{mS}$ $\mathrm{cm}^{-1}$ at different fruit development stages.

\begin{tabular}{llllc}
\hline EC changing stage & Fruit width $(\mathrm{cm})$ & Fruit length $(\mathrm{mm})$ & Fresh weight $(\mathrm{mg})$ & Dry weight $(\mathrm{mg})$ \\
\hline No change (control) & 0.68 & $5.89 \mathrm{ab} 1 /$ & 1.51 & 0.20 \\
1 week after blooming & 0.60 & $5.90 \mathrm{ab}$ & 1.42 & 0.24 \\
2 weeks after blooming & 0.67 & $6.76 \mathrm{a}$ & 1.94 & 0.27 \\
3 weeks after blooming & 0.67 & $5.30 \mathrm{~b}$ & 1.56 & 0.24 \\
4 weeks after blooming & 0.68 & $5.96 \mathrm{ab}$ & 2.08 & 0.31 \\
5 weeks after blooming & 0.71 & $6.72 \mathrm{a}$ & 2.21 & 0.34 \\
CV & 8.38 & 8.90 & 28.65 & 24.52 \\
F-test & $\mathrm{ns}$ & $*$ & $\mathrm{~ns}$ & $\mathrm{~ns}$ \\
\hline
\end{tabular}

ns = Nonsignificant

$*$ = Significant difference at the $95 \%$ level of confidence

$1 /=$ Means followed by a common letter are not significantly different at the $95 \%$ level

Table 2. Fruit number and yield of hot chili affected by the nutrient solution concentration changing at different fruit development stages.

\begin{tabular}{llr}
\hline EC changing stage & Fruit No./Plant & Yield/plant (g/plant) \\
\hline No change (control) & 452.75 & 741.25 \\
1 week after blooming & 423.00 & 691.75 \\
2 weeks after blooming & 442.50 & 720.00 \\
3 weeks after blooming & 447.25 & 739.75 \\
4 weeks after blooming & 443.75 & 733.75 \\
5 weeks after blooming & 450.50 & 737.00 \\
CV. & 2.84 & 3.12 \\
F-test & $\mathrm{ns}$ & $\mathrm{ns}$ \\
\hline
\end{tabular}

ns $=$ Nonsignificant

Table 3. Oleoresin, capsaicin, dihydrocapsaicin and capsaicinoids $(\% \mathrm{w} / \mathrm{w})$ in chili fruits affected by the nutrient solution concentration changing at different fruit development stages.

\begin{tabular}{lllll}
\hline EC changing stage & Oleoresin $(\% \mathrm{w} / \mathrm{w})$ & Capsaicin $(\% \mathrm{w} / \mathrm{w})$ & Dihydrocapsaicin $(\% \mathrm{w} / \mathrm{w})$ & Capsaicinoids $(\% \mathrm{w} / \mathrm{w})$ \\
\hline No change $($ control $)$ & $10.90 \mathrm{c}$ & $0.32 \mathrm{c} 1 /$ & $0.15 \mathrm{c}$ & $0.47 \mathrm{c}$ \\
1 week after blooming & $12.99 \mathrm{a}$ & $0.55 \mathrm{a}$ & $0.20 \mathrm{a}$ & $0.75 \mathrm{a}$ \\
2 weeks after blooming & $12.30 \mathrm{~b}$ & $0.39 \mathrm{~b}$ & $0.16 \mathrm{~b}$ & $0.56 \mathrm{~b}$ \\
3 weeks after blooming & $10.91 \mathrm{c}$ & $0.30 \mathrm{~d}$ & $0.15 \mathrm{c}$ & $0.44 \mathrm{~d}$ \\
4 weeks after blooming & $10.83 \mathrm{c}$ & $0.25 \mathrm{e}$ & $0.10 \mathrm{e}$ & $0.35 \mathrm{e}$ \\
5 weeks after blooming & $10.81 \mathrm{c}$ & $0.29 \mathrm{~d}$ & $0.14 \mathrm{~d}$ & $0.43 \mathrm{~d}$ \\
CV. & 4.19 & 1.44 & 2.08 & 2.04 \\
F-test & $* *$ & $* *$ & $* *$ & $* *$ \\
\hline
\end{tabular}

$* *=$ Significant difference at the $99 \%$ level of confidence

$1 /=$ Means followed by a common letter are not significantly different at the $95 \%$ level

Table 4. PAL activity at mature-green stage and full-ripened stage of chili fruits affected by the nutrient solution concentration increasing at different fruit development stages.

\begin{tabular}{llc}
\hline $\begin{array}{l}\text { EC changing stage } \\
\left(\mathrm{mmole} \mathrm{mg}^{-1} \text { protein }\right)\end{array}$ & $\begin{array}{l}\text { PAL activity at mature green stage } \\
\left(\mathrm{mmole} \mathrm{mg}^{-1} \text { protein }\right)\end{array}$ & $\begin{array}{l}\text { PAL activity at full ripen-ing stage } \\
\left(\mathrm{mmole} \mathrm{mg}^{-1} \text { protein }\right)\end{array}$ \\
\hline No change (Control) & $431.98 \mathrm{a} 1 /$ & $505.18 \mathrm{c}$ \\
1 week after blooming & $351.68 \mathrm{ab}$ & $824.48 \mathrm{a}$ \\
2 weeks after blooming & $379.18 \mathrm{a}$ & $827.48 \mathrm{a}$ \\
3 weeks after blooming & $213.08 \mathrm{c}$ & $584.18 \mathrm{~b}$ \\
4 weeks after blooming & $292.68 \mathrm{bc}$ & $547.48 \mathrm{bc}$ \\
5 weeks after blooming & $259.05 \mathrm{c}$ & $578.08 \mathrm{~b}$ \\
CV. & 14.09 & 5.05 \\
F-test & $* *$ & $* *$ \\
\hline
\end{tabular}

$* *$ = Significant difference at the $99 \%$ level of confidence

$1 /=$ Means followed by a common letter are not significantly different at the $95 \%$ level 
The effect of NSCI treatements found in this cureent experiment differed from Sritong-on (2009) who reported that the application of the NSCI treatment from 2.4 to $4.8 \mathrm{mS} \mathrm{cm}^{-1}$ in the period from $\mathrm{FB}$ to the end of harvest significantly reduced the fruit number and total yield of hot chili as a result of flower drop and from Marcelis et al. (2004) who found the fruit drop phenomenon in sweet pepper plants as an effect of stress occurring at the flowering stage. Firstly, the reason for the difference might be because in the current study, the degree of water stress induced by increasing the nutrient solution concentration from 2.4 to $3.6 \mathrm{mS} \mathrm{cm} \mathrm{cm}^{-1}$ was lower than that in the experiment of Sritong-on (2009) in which the concentration was increased from 2.4 to $4.8 \mathrm{mS} \mathrm{cm}^{-1}$. Secondly, the NSCI treatment was imposed after FB when fruits had already set and become more tolerant to the stress than that of in the flowering stage.

The increase in the nutrient solution concentration should result in a salinity effect to the chili plants which lowered the water potential of the solution around the root zone causing the roots to be subjected to water stress conditions. As a result, this water-stress condition induced the increase of capsaicin and dihydrocapsaicin synthesis (Estrada et al., 1999). Sung et al. (2005) stated that under water stress conditions, plants will increase the production of secondary metabolites, which in the case of chili are capsaicin and dihydropcapsaicin as a protective defensive mechanism. The similar defensive mechanism was also reported by Zushi and Matsuzoe (2009) where salt-induced stressed tomato plants produced more lycopene to serve as an antioxidant in the oxidation-damaging process that occurred during the stress conditions. However, the contradict result of pungency decreasing was found when the salt-induced stress was imposed during the later fruit development stages. This may cause by the higher competition for assimilates between fruit growth and pungent compound synthesis that occurs in the later stages. The rapid growth rate of chili fruit in the later fruit development stage (Bosland and Votava, 2012) might increase the sink strength for the food. Hence, under the salt-induced stress condition where the photosynthesis might also be adversely affected, the majority of assimilates is partitioned for fruit growth than for pungent compound synthesis resulting in pungency reduction as compared to the control.

PAL is the initial enzyme in the Phenyl Propanoid pathway, one of the pathways for capsaicin synthesis. The PAL activity in chili fruit increases gradually as fruit development progresses and reaches the maximum value at the full-ripened stage (Ochoa-Alejo and GomezPeralta, 1993). Its activity is directly related to the pungency level and under water-stress conditions, chili plants use the stress to stimulate PAL activity as the mechanism by which the synthesis of capsaicin and dihydro-capsaicin is increased to cope with the stress effect (Sung et al., 2005). This PAL activity result was in line with the pungency results in which the increased nutrient concentration as early as the 1 st and 2 nd weeks after FB caused a significant increase in the capsaicin and dihydrocapsaicin contents, while the increased nutrient concentration solution in the $3 \mathrm{rd}$ week onward after FB the capsaicin and dihydrocapsaicin contents decreased significantly.

The results in this study also revealed that timing for imposing the stress during chili fruit development played a role in the stimulation of the PAL activity and, consequently, the capsaicinoids synthesis. The application of salt-induced water stress should be imposed as early as the first two weeks after FB in order to stimulate PAL activity and consequently, an increase in capsaicinoid synthesis. In contrast, the late application of the stress 3 weeks after FB can suppress PAL activity in the greenmature fruit stage and consequently, reduce capsaicinoid synthesis.

\section{CONCLUSION}

The result of this experiment reveales that the pungency of the hot chilli can be enhanced sucessfully without causing the yield reduciton through the stimulation PAL acitivity by imposing the optimum degree of salt-induced water stress to the plant at 1 or 2 weeks after blooming week.

\section{ACKNOWLEDGEMENT}

The researchers would like to thank the Kasetsart University Research and Development Institute (KURDI), Thailand for providing research funds for this experiment.

\section{REFERENCES}

Albright, L.D., 2002. Controlling Greenhouse Environments. Proceedings of the International Symposium on Design and Environmental Control of Tropical and Subtropical Greenhouses, (DECTSG' 02), pp: 47-53.

Barceloux, D.G., 2009. Pepper and capsaicin (Capsicum and Piper species). Dis. Mon., 55: 380-390. DOI: 10.1016/j.disamonth.2009.03.008 
Bosland, P.W. and E.J. Votava, 2012. Peppers: Vegetable and Spice Capsicums (Crop Production Science in Horticulture). 2nd Edn., CABI Publishing, Cambridge, UK., ISBN-10: 1845938259, pp: 248.

Bradford, M., 1976. A rapid and sensitive method for the quantitation of microgram quantities of protein utilizing the principle of protein-dry binding. Anal. Biochem., 72: 248-254. DOI: 10.1016/00032697(76)90527-3

Collins, M.D., L. Mayer-Wasmund and P.W. Bosland, 1995. Improved method for quantifying capsaicinoids in capsicum using high-performance liquid chromatography. Hort. Sci., 30: 137-139.

Customs, T., 2013. Import and export statistics.

Estrada, B., F. Pomar, J. Díaz, F. Merino and M.A. Bernal, 1998. Effects of mineral fertilizer supplementation on fruit development and pungency in 'padron' peppers. J. Hort. Sci. Biotechnol., 74: 493-497.

Estrada, B., F. Pomar, J. Diaz, F. Merino and M.A. Bernal, 1999. Pungency level in fruits of the Padrón pepper with different water supply. Scient. Hort., 81: 385-396. DOI: 10.1016/S0304-4238(99)00029-1

Faragher, J.D. and D.J. Chalmers, 1977. Regulation of anthocyanin synthesis in apple skin III. Involvement of phenylalanine ammonia-lyase. Aust. J. Plant Physiol., 4: 133-141. DOI: 10.1071/PP9770133

Hall, R.D., M.A. Holden and M.M. Yeoman, 1987. The accumulation of phenylpropanoid and capsaicinoid compounds in cell cultures and whole fruit of the chilli pepper, Capsicum frutescens Mill. Plant Cell Tiss. Organ. Cult., 8: 163-176. DOI: 10.1007/BF00043153

Jensen, M.H., 2002. Controlled environment in the tropic and temperate regions-a review. Chen Ent. Agric. Deserts, 578: 19-25.

Lertrat, K., 2007. The production, cultivation, processing and marketing of chili and chili products in Thailand.

Marcelis, L.F.M., E. Heuvelink, L.R.B. Hofman-Eijer, J.D. Bakker and L.B. Xue, 2004. Flower and fruit abortion in sweet pepper in relation to source and sink strength. J. Exp. Botany, 55: 2261-2268. DOI: 10.1093/jxb/erh245

Margarita, C. and M. Yahia, 1998. Changes in capsaicinoids during development, maturation and senescence of chile peppers and relation with peroxidase activity. J. Agric. Food Chem., 46: 20752079. DOI: $10.1021 / j f 970972 z$
Moller, M., J. Tanny, Y. Li and S. Cohen, 2004. Measuring and predicting evaporation in an insectproof screen-house. Agric. Forest Meteorol., 127: 35-51. DOI: 10.1016/j.agrformet.2004.08.002

Narasimha, P.BC., HB. Gururaj, V. Kumar, P. Giridhar and R. Parimalan et al., 2006. Influence of 8methyl-nonenoic acid on capsaicin biosynthesis in in-vivo and in-vitro cell cultures of Capsicum spp. J. Agric. Food Chem., 54: 1854-1859. DOI: $10.1021 / \mathrm{jf052085z}$

Ochoa-Alejo, N. and J.E. Gomez-Peralta, 1993. Activity of enzymes involved in capsaicin biosynthesis in callus tissue and fruits of chili pepper (Capsicum annuum L.). J. Plant Physiol., 141: 147-152. DOI: 10.1016/S0176-1617(11)80751-0

Panklang, P., 2004. Fruit characteristics, oleoresin contents and pungency levels of capsicum. M.Sc. Thesis, Kasetsart University, Nakhon Pathom.

Prapanoppasin, P., 2001. Comparison of extraction techniques of capsaicin contents in capsicum cultivars. M.Sc. Thesis, Kasetsart University. Nakhon Pathom, Thailand.

Prinya, W., N. Rungraeng and A. Khuanpet, 2009. Process and factors affecting on quality on grounded peppers. Final Report (Thai) The Thailand Research Fund, Bangkok, Thailand.

Rubatzky, V.E. and M. Yamaguchi, 1997. World Vegetables: Principles, Production and Nutritive Values. 2nd Edn., Springer, New York, ISBN-10: 0834216876, pp: 704.

Sritong-on, P., 2009. Effect of nutrient solution concentrations on growth, yield and pungency of Chili (Capsicum annuum L.) grown in substrate. B.Sc. Thesis, Kasetsart Univeristy, Nakhon Pathom, Thailand.

Summer, J., 2012. How to build a greenhouse and how to garden in it. Printed in United States of America.

Sung, Y., Y.Y. Chang and N. L. Ting, 2005. Capsaicin biosynthesis in water-stresses hot pepper fruits. Bot. Bull. Acad. Sin, 46: 35-42.

Zushi, K. and N. Matsuzoe, 2009. Seasonal and cultivar differences in salt-induced changes in antioxidant system in tomato. Scientia Hort., 120: 181-187. DOI: $10.1016 /$ j.scienta.2008.10.005 